\title{
Development of a reverse transcription recombinase polymerase amplification assay with lateral flow dipstick for rapid detection of classical swine fever virus
}

\section{Jindai Fan}

South China Agricultural University

Yuanyuan Zhang

South China Agricultural University

Wenxian Chen

South China Agricultural University

Jingyuan Zhang

South China Agricultural University

Chenchen Liu

South China Agricultural University

Mengru Zhang

South China Agricultural University

Hongxing Ding

South China Agricultural University

Lin Yi

South China Agricultural University

Jinding Chen

South China Agricultural University

Mingqiu Zhao ( $\nabla$ zmingqiu@scau.edu.cn )

South China Agricultural University College of Veterinary medicine https://orcid.org/0000-0002-69609354

Research article

Keywords: classical swine fever virus, diagnosis, recombinase polymerase amplification, lateral flow dipstick.

Posted Date: September 8th, 2020

DOI: https://doi.org/10.21203/rs.3.rs-71548/v1 
License: (c) (i) This work is licensed under a Creative Commons Attribution 4.0 International License. Read Full License 


\section{Abstract}

Background: Classical swine fever (CSF), caused by the infection of Classical swine fever virus (CSFV), is a highly contagious disease of pigs and has caused significant economic losses in the pig industry. The rapid and effective detection of CSFV would contribute to the eradication program against CSF. Thus, this study aimed to develop a rapid and simple method for CSFV detection.

Results: Here, a new method based on reverse transcription recombinase polymerase amplification (RTRPA) coupled with lateral flow dipstick (LFD) was established for detecting CSFV. The RPA assay could be completed within 20 min at $37^{\circ} \mathrm{C}$ and the results of the RPA assay could be visualized by LFD assay with the naked-eye inspection. This RT-RPA-LFD assay could be used to detect CSFV specifically, with no cross-reaction with other pathogens. Its detection limit was $10 \mathrm{pg}$ of CSFV cDNA. Importantly, the RT-RPALFD assay has a good performance on the CSFV detection for clinical samples.

Conclusions: The established RT-RPA-LFD assay greatly reduced the need for professional staff and sophisticated instruments and made disease detection convenient and feasible. This method would be useful for the prevention and control of CSF, especially in resource-limited settings.

\section{Background}

Classical swine fever (CSF) is an economically important, highly contagious disease affecting pigs worldwide, characterized by high fever, hemorrhagic syndrome, and high mortality $[1,2]$. The causative agent of CSF is the classical swine fever virus (CSFV), an enveloped RNA virus that belongs to the Pestivirus within the family Flaviviridae [3, 4]. Many molecular diagnostic methods for CSFV detection require sophisticated instruments, which is not convenient for clinical detection. Thus, it is necessary to establish a rapid and simple diagnosis method for CSFV detection, which is critical for CSF prevention and control.

Recombinase polymerase amplification (RPA) is a novel technique of DNA isothermal amplification, which can complete the amplification of target sequence in a short time by simulating DNA replication in vivo without the temperature cycle. The RPA assay has the advantages of rapidity, specificity, and sensitivity, and doesn't need expensive instruments $[5,6]$. After the RPA assay, lateral flow dipstick (LFD) could be used to detect the products of DNA amplification [7]. Recently, RPA assay coupled with LFD assay (RPA-LFD) has been reported to have a good potential in the detection of many pathogens, such as bovine ephemeral fever virus, African swine fever virus, and avian influenza A virus [8-10]. As it is rapid, convenient, and efficient for pathogen detection, RPA-LFD is gradually gaining favor from researchers.

In this work, we developed a reverse transcription recombinase polymerase amplification assay coupled with lateral flow dipstick (RT-RPA-LFD) for CSFV detection. The established method had the advantages of rapidity, sensitivity, and specificity, which had good potential in clinical application.

\section{Results}




\section{Screening of primers and probe for RPA assay}

Several pairs of primers combined with different probes were designed and then a pair of primers (CSFVF1 and CSFV-R1) combined with the probe CSFV-P were selected for subsequent evaluation through screening (Table 1, only the optimal primers and probe were listed). As shown in Fig. 1, the positive sample (CSFV, shimen strain) could produce two red-purple lines that appeared on the LFD test strip ( $T$ and $C$ line), while negative control produced only one red-purple line ( $C$ line).

Table 1

Primers and probe for CSFV RT-RPA-LFD assay in this study

\begin{tabular}{|llc|}
\hline Primer/probe & Sequence (5' $^{\prime} \mathbf{3}^{\prime}$ ) & $\begin{array}{c}\text { Genome } \\
\text { position }\end{array}$ \\
\hline CSFV-F1 & CCGACGGGGAAGTATACATAAGGAAAGGGC & $11088-$ \\
\hline CSFV-R1 & CCTTGCTCGCGAATTTCTCACCGAGAGCTC & $11117 \mathrm{nt}$ \\
\hline CSFV-P & FAM-CAAAGAGGCAGCGGACAACCTGACACAAGC-THF- & $11280-$ \\
& CAGGCAATAGCATGC-C3 spacer & $11309 \mathrm{nt}$ \\
\hline $\begin{array}{l}\text { CSFV-F and CSFV-R, RPA primers; CSFV-P, RPA-nof probe; FAM, carboxyfluorescein; } \text { THF, } \\
\text { tetrahydrofuran spacer; C3 spacer, polymerase extension blocking group. }\end{array}$ \\
\hline
\end{tabular}

\section{Optimization of RPA conditions}

We tested different reaction temperature $\left(15^{\circ} \mathrm{C}, 20^{\circ} \mathrm{C}, 25^{\circ} \mathrm{C}, 30^{\circ} \mathrm{C}, 35^{\circ} \mathrm{C}, 37^{\circ} \mathrm{C}, 40{ }^{\circ} \mathrm{C}, 45^{\circ} \mathrm{C}\right.$, and $50^{\circ} \mathrm{C}$, respectively) for RPA assay with the same incubation time (20 $\mathrm{min})$ to screen the optimal temperature. As shown in Fig. 2, when the reaction temperature was $\leq 25^{\circ} \mathrm{C}$ or $\geq 50^{\circ} \mathrm{C}$, only the control line (C line) was detected on the test strip. The red-purple bands both at $\mathrm{T}$ line and $\mathrm{C}$ line were detected and did not show significant differences between $30^{\circ} \mathrm{C}$ and $45^{\circ} \mathrm{C}$. Thus, $37^{\circ} \mathrm{C}$ was selected as the reaction temperature for subsequent research. We next tested different incubation time (1 min, $5 \mathrm{~min}, 10 \mathrm{~min}, 20 \mathrm{~min}, 25 \mathrm{~min}$, and 30 min, respectively) for obtaining the optimal RPA incubation time. As shown in Fig. 3, when the incubation time was $\geq 10 \mathrm{~min}$, the red-purple bands on $\mathrm{T}$ line were obvious and did not show significant differences. Then, 20 min was selected as the incubation time for RPA assay.

\section{The specificity of CSFV RT-RPA-LFD assay}

To evaluate the specificity of CSFV RT-RPA-LFD assay, different species of viruses including CSFV, PEDV, PPV, PRV, PRRSV, PCV2, and JEV were tested. As shown in Fig. 4, no T line appeared in all samples except CSFV positive sample, which indicated that the established RT-RPA-LFD assay was specific for CSFV detection. 
The sensitivity of CSFV RT-RPA-LFD assay was evaluated with 10-fold serial dilutions of CSFV cDNA and compared with that of RT-PCR. Results revealed that the detection limit of both RT-RPA-LFD and RT-PCR were 10 pg of CSFV cDNA (data not shown).

\section{Performance of RT-RPA-LFD assay on samples from experimentally infected pigs}

To validate the performance of the newly developed RT-RPA-LFD assay, a total of twelve samples including inguinal lymph nodes, spleen, thymus, and tonsil from three pigs experimentally infected with CSFV were detected by RT-RPA-LFD assay and RT-PCR. We found that these twelve samples were positive by RT-RPA-LFD assay and also positive by RT-PCR (data not shown).

\section{Discussion}

CSF is one of the most devastating diseases for the pig industry and has caused severe economic losses worldwide [11]. At present, CSF is still endemic in many Asian and Latin American countries, as well as in some countries from Eastern Europe $[12,13]$. Due to the huge harm of this disease, many countries have developed the eradication program against CSF [4]. What's more, our team has been working on the research of the pathogenesis of CSF, as well as the prevention and control of CSF [14-16]. We realize that rapid diagnostics of CSFV infection is conducive to the eradication program against CSF. Therefore, we would like to establish a rapid and efficient method for CSFV detection with high sensitivity and specificity. We then focus on the isothermal amplification assays, as they could work with a constant temperature device and don't rely on complex specialized equipment. We found that many kinds of isothermal amplification methods, such as RPA assay [17], loop-mediated isothermal amplification assay (LAMP) [18], cross-priming amplification (CPA) [19], and polymerase cross-linking spiral reaction (PCLSR) [20], had been established and widely used for the diagnosis of infectious disease. As an alternative to PCR-based method, RPA assay is an efficient tool for the rapid diagnosis of infectious disease, especially in resource-limited settings. Furthermore, RPA assay combined with a visual analysis system, such as lateral flow dipstick (LFD), is more conducive to clinical disease diagnosis. Considering that RPA-LFD assay is simple and easy to be performed as sophisticated equipment, specialized laboratories and complex experimental procedures are needless, the establishment of RT-RPA-LFD assay is valuable for clinical CSFV detection.

When establishing the RT-RPA-LFD assay, we first focused on the selection of optimal RPA primers and probe. The design of RPA primers and probes is the key point for RPA assay. We designed and verified different primer pairs and probes (data not shown). After screening, a pair of primers (CSFV-F and CSFVR) combined with a probe (CSFV-P) was the final choice for RPA assay (Table 1). Then, the reaction temperature was tested as it was a key parameter for the RPA assay. We found that lower $\left(\leq 25^{\circ} \mathrm{C}\right)$ or higher temperature $\left(\geq 50^{\circ} \mathrm{C}\right)$ was not suitable for DNA amplification, which might be due to the low enzyme activity under lower or higher temperature. The RPA assay could work well in a wide range of temperatures $\left(30 \sim 45^{\circ} \mathrm{C}\right.$ ) with no significant difference and $37^{\circ} \mathrm{C}$ was selected as reaction temperature for RPA assay as this temperature $\left(37^{\circ} \mathrm{C}\right)$ was a very common parameter and could be easily accepted 
by most people. After optimizing the reaction temperature, we tested the incubation time in the subsequent experiment. We found that the target sequence could not be effectively amplified within a too short time. However, amplification with a long time was not a good choice for rapid diagnosis. Thus, 20 min was chosen as the incubation time for RPA assay. Furthermore, the specificity and sensitivity of CSFV RT-RPA-LFD assay were evaluated. The results suggested the established RT-RPA-LFD assay was specific for the detection of CSFV and its sensitivity was similar to that of the RT-PCR. Finally, the performance of CSFV RT-RPA-LFD assay on samples from experimentally infected pigs was validated. We found that a total of twelve samples including inguinal lymph nodes, spleen, thymus, and tonsil from three pigs experimentally infected with CSFV (shimen strain) were positive by RT-RPA-LFD assay and also positive by RT-PCR, which suggested that CSFV RT-RPA-LFD assay had the potential to be a valuable tool for clinical diagnosis of CSF.

\section{Conclusions}

The CSFV RT-RPA-LFD assay was successfully developed for CSFV detection with good specificity and sensitivity in this work. The RPA assay could be completed within 20 min at $37^{\circ} \mathrm{C}$ and the results of the RPA assay could be visualized by LFD assay with the naked-eye inspection. The established method greatly reduced the need for professional staff and sophisticated instruments, which made disease detection convenient and feasible. This method would be useful for the prevention and control of CSF, especially in resource-limited settings.

\section{Methods}

\section{Virus and samples}

CSFV (shimen strain), Porcine epidemic diarrhea virus (PEDV, CV777 strain), Porcine parvovirus (PPV, GDQY/2010/01 strain), Pseudorabies virus (PRV, Ea strain), Porcine reproductive and respiratory syndrome virus (PRRSV, 08 - 2 strain), Japanese encephalitis virus (JEV, JEV/sw/GD/2009 strain), and Porcine circovirus type 2 (PCV2, LG strain) were preserved in our laboratory. A total of twelve samples including inguinal lymph nodes, spleen, thymus, and tonsil from three pigs experimentally infected with CSFV (shimen strain) in our previous work were preserved in our laboratory. These samples were tested for CSFV by RT-RPA-LFD assay and RT-PCR.

\section{Isolation of viral DNA/RNA and synthesis of CDNA}

Viral DNA/RNA was extracted from samples using a Viral DNA/RNA Extraction Kit (OMEGA Bio-Tek, USA) according to the manufacturer's instructions. The viral CDNA was synthesized using M-MLV reverse transcriptase (TAKARA Biotechnology, Dalian, China) according to the manufacturer's instructions. All viral DNA, RNA, and cDNA were stored at $-80^{\circ} \mathrm{C}$ for further employment.

\section{CSFV RT-PCR assay}


The CDNA of CSFV was synthesized as above and used for PCR amplification. The primers used for PCR were CSFV-f (5'-CTAGCCATGCCCWYAGTAGG-3') and CSFV-r (5'-CAGCTTCARYGTTGATTGT-3'). A 421 bp fragment within $5^{\prime}$-UTR region of the CSFV genome was amplified. The amplification was performed in a $25 \mu \mathrm{L}$ volume containing $2 \times$ Taq PCR StarMix $(12.5 \mu \mathrm{L}), \mathrm{ddH}_{2} \mathrm{O}(8.5 \mu \mathrm{L})$, the forward and reverse primers (10 $\mu \mathrm{M}, 1 \mu \mathrm{L}$ each) and cDNA template $(2 \mu \mathrm{L})$. PCR amplification was performed as follows: $5 \mathrm{~min}$ of initial denaturation at $94{ }^{\circ} \mathrm{C}, 35$ cycles of $30 \mathrm{~s}$ of denaturing at $94{ }^{\circ} \mathrm{C}, 30 \mathrm{~s}$ of annealing at $55^{\circ} \mathrm{C}$, and $30 \mathrm{~s}$ of extension at $72{ }^{\circ} \mathrm{C}$. The $10 \mathrm{~min}$ of extension at $72{ }^{\circ} \mathrm{C}$ was added after the 35 -cycle amplification. The PCR products were detected with $1 \%$ agarose gels.

\section{CSFV RT-RPA-LFD assay}

The cDNA of CSFV was synthesized as above and used for RPA assay. RPA primers and probes were designed according to the parameter requirements of the TwistAmp ${ }^{\text {TM }}$ nfo RPA kit manual (TwistDx ${ }^{\text {TM }}$ Limited, Cambridge, UK) based on the CSFV genome sequence (GenBank Accession number: HQ380231) using Primer Premier 5.0. The reverse primer was labeled with a biotin at the $5^{\prime}$ end and the nfo-probe carried a fluorescein FAM at the $5^{\prime}$ end, an internal tetrahydrofuran residue (THF) at 30 bp from the $5^{\prime}$ end, and a C3 spacer at the 3' end (Table 1). All the primers and probes were synthesized by Sangon Biotech (Shanghai, China). The RPA assay was performed in a $50 \mu \mathrm{L}$ final reaction volume according to the instructions of the TwistAmp ${ }^{\text {TM }}$ RPA nfo kit (TwistDx ${ }^{T M}$ Limited, Cambridge, UK). In brief, the rehydration solution contained $4 \mu \mathrm{L}$ cDNA template, $2.1 \mu \mathrm{L}$ of forward primer $(10 \mu \mathrm{M}), 2.1 \mu \mathrm{L}$ of reverse primer $(10 \mu \mathrm{M}), 0.6 \mu \mathrm{L}$ of the probe $(10 \mu \mathrm{M}), 9.2 \mu \mathrm{L}$ of $\mathrm{ddH}_{2} \mathrm{O}$, and $29.5 \mu \mathrm{L}$ rehydration buffer (TwistDx ${ }^{\mathrm{TM}}$ Limited, Cambridge, UK). The dried enzyme pellet in a $0.2 \mathrm{~mL}$ tube strip provided by the TwistAmp ${ }^{\text {TM }}$ RPA nfo kit was resuspended with $47.5 \mu \mathrm{L}$ of the rehydration solution, and then the reaction was initiated by adding $2.5 \mu \mathrm{L}$ of magnesium acetate $(280 \mathrm{mM})$. Experiments were performed to optimize the RPA assay by testing different incubation time and amplification temperature. The RPA result was directly determined using lateral flow dipstick (LFD) visualization strip cassette (Ustar Biotech, Hangzhou, China). The manipulation procedure of the LFD visualization strip cassette was shown in Fig. 5A. Firstly, the reaction tube was pushed transversely into the amplicon cartridge. Next, the cartridge was closed and inserted into the detection chamber. Then, the handle of the detection chamber was pressed to be sealed. Once the handle being closed, both the reaction tube and the bulb containing the running buffer were cut by the razor blade and the amplicon products mixed with the running buffer and flowed to the DNA detection strip which was implanted into the cassette through a fiberglass paper. One to two minutes after the handle being closed, the result could be determined based on the displayed bands from the detection window of the chamber. As shown in Fig. 5B, the red-purple bands both at $T$ line and $C$ line could be detected in the positive sample while only one band ( $\mathrm{C}$ line) appeared for a negative sample.

\section{The specificity and sensitivity of CSFV RT-RPA-LFD assay}

The specificity of CSFV RT-RPA-LFD assay was evaluated by detecting different species of viruses including CSFV, PEDV, PPV, PRV, PRRSV, PCV2, and JEV. The sensitivity of the RT-RPA-LFD assay and RTPCR were compared by detecting ten-fold serial dilutions of CSFV cDNA. 


\section{List Of Abbreviations}

CSF: Classical swine fever; CSFV: Classical swine fever virus; CPA: cross-priming amplification; JEV: Japanese encephalitis virus; LAMP: loop-mediated isothermal amplification assay; LFD: lateral flow dipstick; PCR: Polymerase chain reaction; PEDV: Porcine epidemic diarrhea virus; PPV: Porcine parvovirus; PRV: Pseudorabies virus; PRRSV: Porcine reproductive and respiratory syndrome virus; PCV2: Porcine circovirus type 2; PCLSR: polymerase cross-linking spiral reaction; RT: reverse transcription; RPA: recombinase polymerase amplification; UTR: Untranslated region

\section{Declarations}

\section{Ethics approval and consent to participate}

This study was approved by the Animal Research Committees of South China Agricultural University.

\section{Consent for publication}

Not applicable.

\section{Availability of data and materials}

The data supporting the results of the study were included in the manuscript.

\section{Competing interests}

The authors declare that they have no competing interests.

\section{Funding}

This work was supported by the National Key Research and Development Program of China (Nos. 2016YFD0500700, 2017YFD0501104), the Natural Science Foundation of China (Nos. 31672590), and the Science and Technology Program of Guangzhou, China (Nos. 201803020005).

\section{Authors' contributions}

HXD, LY, JDC, and MQZ conceived and designed the experiments. JDF, JYZ, CCL, and MRZ performed the experiments. YYZ, WXC, and JYZ analyzed the data. JDF wrote the paper. All the authors read and approved the final manuscript.

\section{Acknowledgements}

Not applicable.

\section{References}


1. Kleiboeker SB. Swine fever: classical swine fever and African swine fever. Vet Clin North Am Food Anim Pract. 2002;18:431-451.

2. Lohse L, Nielsen J, Uttenthal A. Early pathogenesis of classical swine fever virus (CSFV) strains in Danish pigs. Vet Microbiol. 2012;159:327-336.

3. Becher P, Avalos Ramirez R, Orlich M, Cedillo Rosales S, Konig M, Schweizer M, et al. Genetic and antigenic characterization of novel pestivirus genotypes: implications for classification. Virology. 2003;311:96-104.

4. Shen $\mathrm{H}$, Wang J, Dong X, Zhao M, Kang Y, Li Y, et al. Genome and molecular characterization of a CSFV strain isolated from a CSF outbreak in South China. Intervirology. 2013;56:122-133.

5. Daher RK, Stewart G, Boissinot M, Bergeron MG. Recombinase Polymerase Amplification for Diagnostic Applications. Clin Chem. 2016;62:947-958.

6. Li J, Macdonald J, von Stetten F. Review: a comprehensive summary of a decade development of the recombinase polymerase amplification. Analyst. 2018;144:31-67.

7. Wang Z, Wang X, Hou S. Development of a recombinase polymerase amplification assay with lateral flow dipstick for rapid detection of feline parvovirus. J Virol Methods. 2019;271:113679.

8. Hou P, Zhao G, Wang H, He C, Huan Y, He H. Development of a recombinase polymerase amplification combined with lateral-flow dipstick assay for detection of bovine ephemeral fever virus. Mol Cell Probes. 2018;38:31-37.

9. Miao F, Zhang J, Li N, Chen T, Wang L, Zhang F, et al. Rapid and Sensitive Recombinase Polymerase Amplification Combined With Lateral Flow Strip for Detecting African Swine Fever Virus. Front Microbiol. 2019;10:1004.

10. Ma S, Li X, Peng B, Wu W, Wang X, Liu H, et al. Rapid Detection of Avian Influenza A Virus (H7N9) by Lateral Flow Dipstick Recombinase Polymerase Amplification. Biol Pharm Bull. 2018;41:1804-1808.

11. Paton DJ, Greiser-Wilke I. Classical swine fever-an update. Res Vet Sci. 2003;75:169-178.

12. Chander V, Nandi S, Ravishankar C, Upmanyu V, Verma R. Classical swine fever in pigs: recent developments and future perspectives. Anim Health Res Rev. 2014;15:87-101.

13. Ji W, Guo Z, Ding N, He C. Studying classical swine fever virus: making the best of a bad virus. Virus Res. 2015;197:35-47.

14. Pei J, Deng J, Ye Z, Wang J, Gou H, Liu W, et al. Absence of autophagy promotes apoptosis by modulating the ROS-dependent RLR signaling pathway in classical swine fever virus-infected cells. Autophagy. 2016;12:1738-1758.

15. Pei J, Zhao M, Ye Z, Gou H, Wang J, Yi L, et al. Autophagy enhances the replication of classical swine fever virus in vitro. Autophagy. 2014;10:93-110.

16. Yuan J, Zhu M, Deng S, Fan S, Xu H, Liao J, et al. Classical swine fever virus induces pyroptosis in the peripheral lymphoid organs of infected pigs. Virus Res. 2018;250:37-42.

17. Zhao G, Wang H, Hou P, Xia X, He H. A lateral flow dipstick combined with reverse transcription recombinase polymerase amplification for rapid and visual detection of the bovine respirovirus 3 . 
Mol Cell Probes. 2018;41:22-26.

18. James HE, Ebert K, McGonigle R, Reid SM, Boonham N, Tomlinson JA, et al. Detection of African swine fever virus by loop-mediated isothermal amplification. J Virol Methods. 2010;164:68-74.

19. Frączyk M, Woźniakowski G, Kowalczyk A, Niemczuk K, Pejsak Z. Development of cross-priming amplification for direct detection of the African Swine Fever Virus, in pig and wild boar blood and sera samples. Lett Appl Microbiol. 2016;62:386-391.

20. Wozniakowski G, Fraczyk M, Kowalczyk A, Pomorska-Mol M, Niemczuk K, Pejsak Z. Polymerase cross-linking spiral reaction (PCLSR) for detection of African swine fever virus (ASFV) in pigs and wild boars. Sci Rep. 2017;7:42903.

\section{Figures}

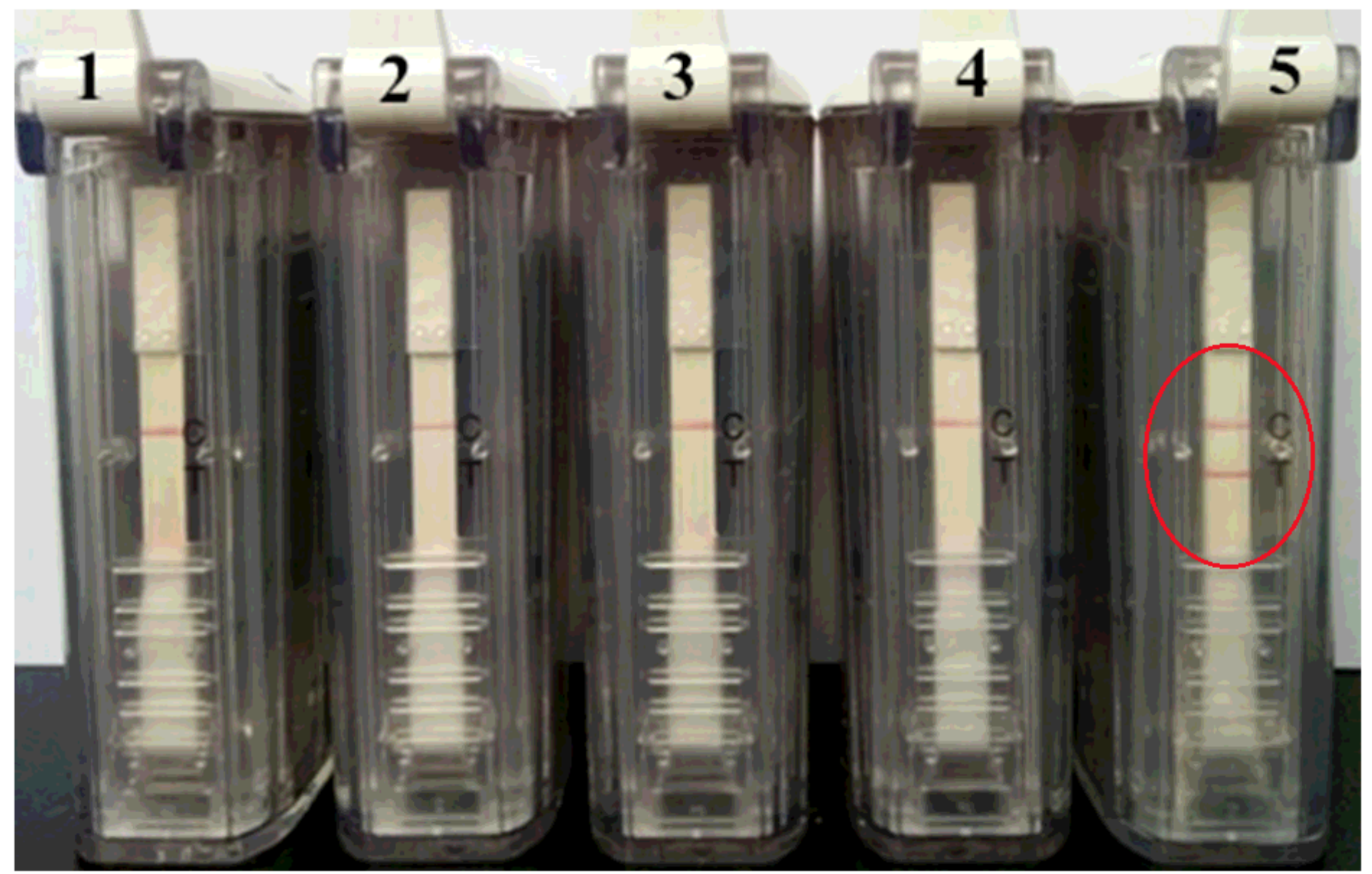

\section{Figure 1}

RT-RPA-LFD assay for CSFV detection. Lane 1, negative control (ddH2O); Lane 2, negative control (negative blood); Lane 3, negative control (negative cell culture supernatant); Lane 4, negative control (negative tonsil tissue); Lane 5, positive sample (CSFV, shimen strain). 


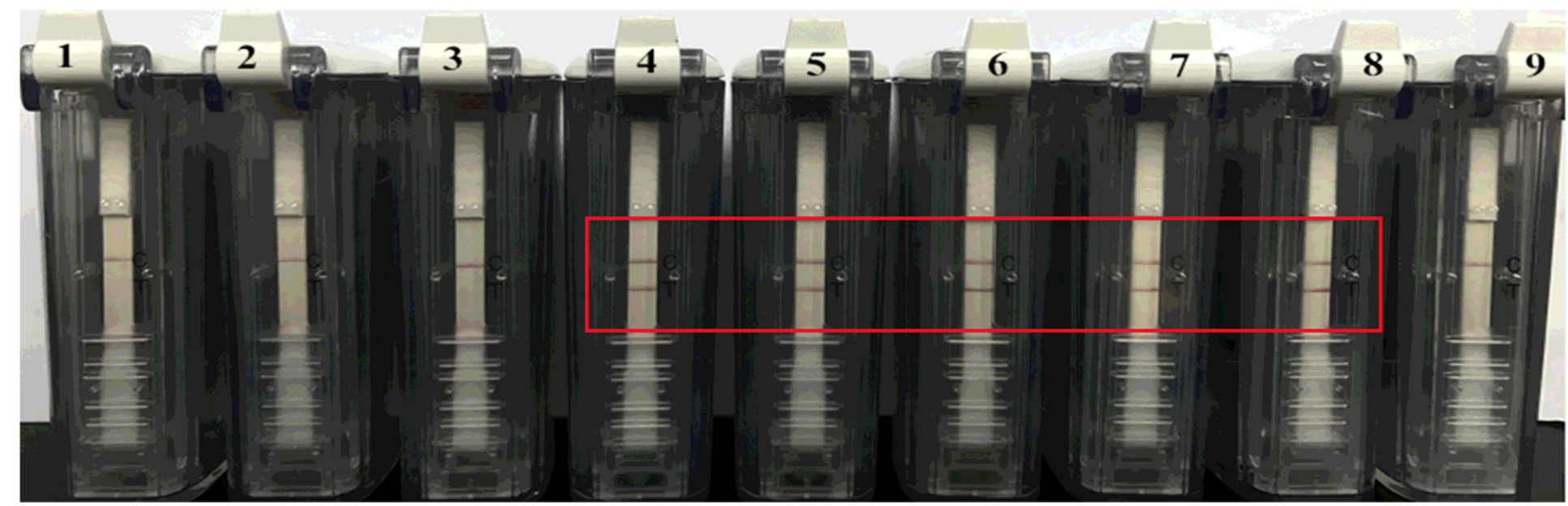

\section{Figure 2}

Optimization of the reaction temperature for the RPA assay. Lane $1-9: 15^{\circ} \mathrm{C}, 20^{\circ} \mathrm{C}, 25^{\circ} \mathrm{C}, 30^{\circ} \mathrm{C}, 35^{\circ} \mathrm{C}, 37^{\circ} \mathrm{C}$, $40^{\circ} \mathrm{C}, 45^{\circ} \mathrm{C}$, and $50^{\circ} \mathrm{C}$, respectively.

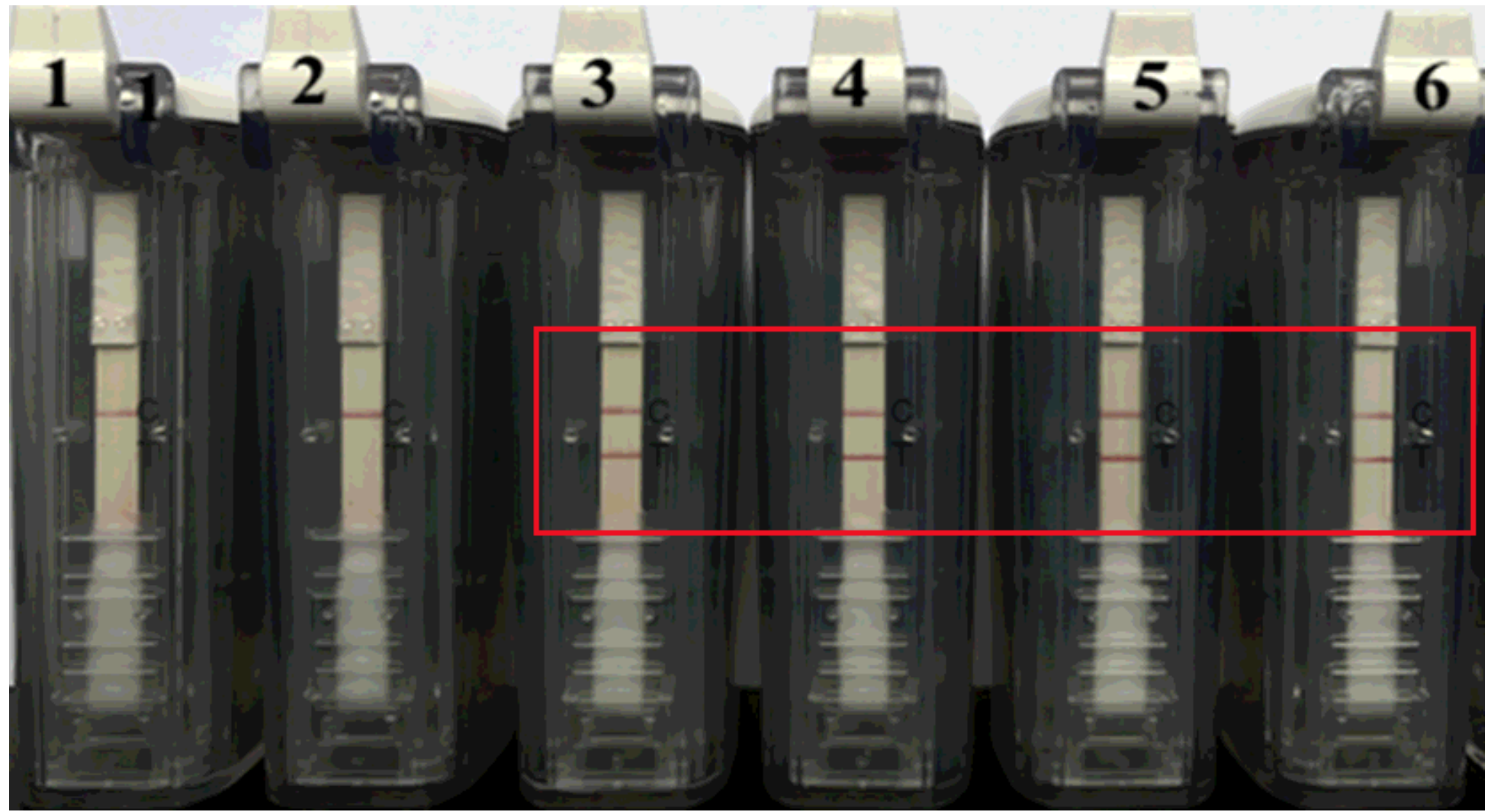

Figure 3

Optimization of the incubation time for RPA assay. Lane 1-6: $1 \mathrm{~min}, 5 \mathrm{~min}, 10 \mathrm{~min}, 20 \mathrm{~min}, 25 \mathrm{~min}$, and 30 min, respectively. 


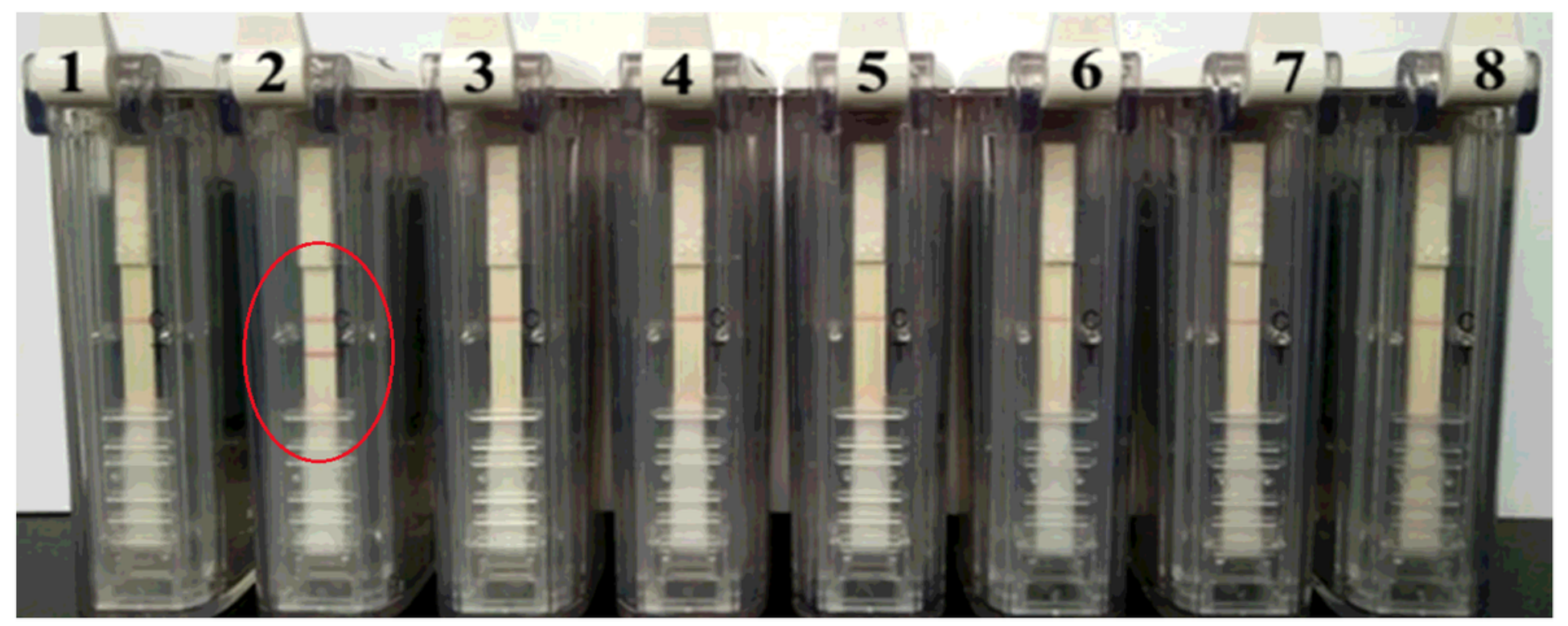

Figure 4

Evaluation of the specificity of RT-RPA-LFD assay. Lane 1-8: ddH2O, CSFV, PEDV, PRRSV, PPV, PRV, PCV2, and JEV, respectively.

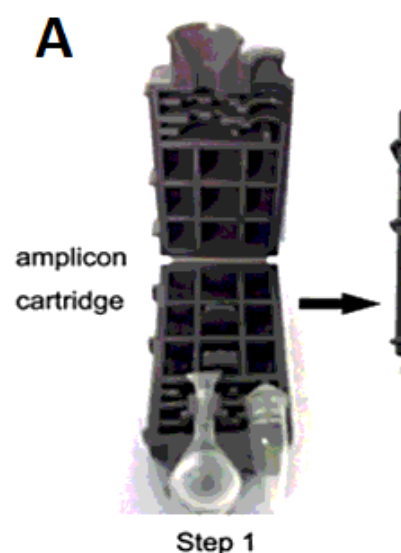

Step 1

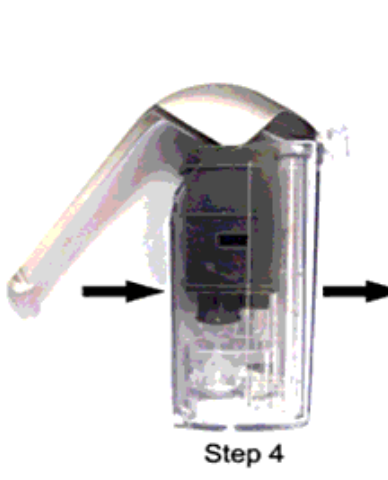

Figure 5
B

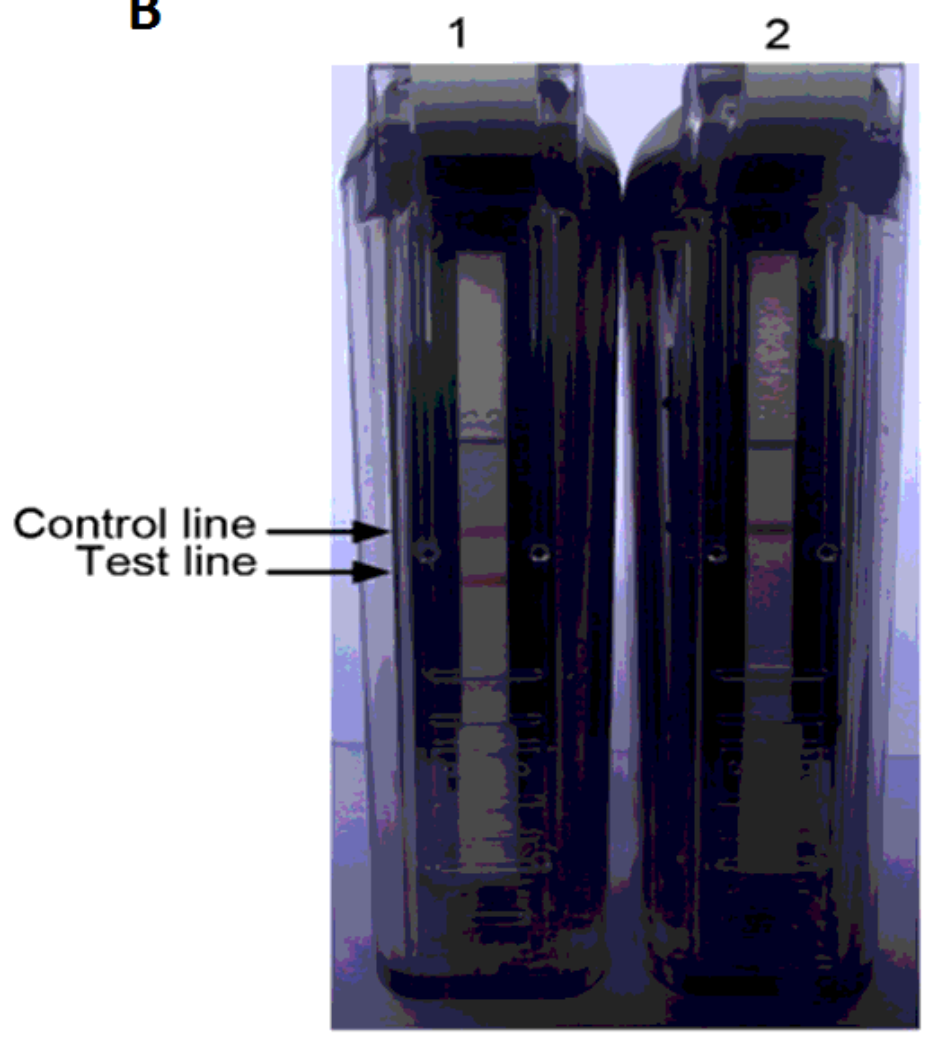

Lateral flow dipstick (LFD) assay. (A) The manipulation procedure of the LFD visualization strip cassette. Step 1, push the reaction tube transversely into the amplicon cartridge; step 2, close the cartridge; step 3 , 
insert the amplicon cartridge into the detection chamber; step 4 5, press the handle of the detection chamber to seal the chamber and to cut off the reaction tube and the bulb containing running buffer; step 6, after 1-2 min, determine the result based on the bands displayed on the detection window of the chamber. (B) the result of the LFD assay. 1, the red-purple bands both at $T$ line and $C$ line could be detected in a positive sample; 2 , only one band ( $\mathrm{C}$ line) appeared for a negative sample. 